\title{
Denis Diderot, Éléments de physiologie
}

\author{
Irene Panighetti
}

\section{(2) OpenEdition}

\section{Journals}

\section{Edizione digitale}

URL: http://journals.openedition.org/studifrancesi/33293

DOI: 10.4000/studifrancesi.33293

ISSN: 2421-5856

\section{Editore}

Rosenberg \& Sellier

\section{Edizione cartacea}

Data di pubblicazione: 1 décembre 2005

Paginazione: 650-651

ISSN: 0039-2944

\section{Notizia bibliografica digitale}

Irene Panighetti, «Denis Diderot, Éléments de physiologie», Studi Francesi [Online], 147 (XLX | III) | 2005,

online dal 30 novembre 2015, consultato il 19 avril 2021. URL: http://journals.openedition.org/

studifrancesi/33293 ; DOI: https://doi.org/10.4000/studifrancesi.33293

\section{Questo documento è stato generato automaticamente il 19 avril 2021.}

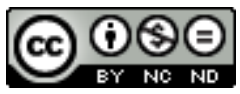

Studi Francesi è distribuita con Licenza Creative Commons Attribuzione - Non commerciale - Non opere derivate 4.0 Internazionale. 


\title{
Denis Diderot, Éléments de physiologie
}

\author{
Irene Panighetti
}

\section{NOTIZIA}

DENIS DIDEROT, Éléments de physiologie, Texte établi, présenté et commenté par Paolo QUINTILI, Paris, Honoré Champion («L'âge des Lumières», 27), 2004, pp. 506.

1 Paolo Quintili propone un'edizione critica degli Éléments de physiologie di Denis Diderot, seguendo criteri editoriali dichiaratamente pedagogici, per orientare chi legge nel labirintico pensiero di Diderot; a tal fine, nelle numerose e precise note, il curatore riporta citazioni dalle opere del philosophe che hanno legami diretti o indiretti con il testo presentato.

Gli Éléments de physiologie sono preceduti da una lunga introduzione, nella quale Paolo Quintili cerca di tratteggiare l'orizzonte scientifico-filosofico in cui si colloca il testo di Diderot e di ricostruirne la genesi; egli riassume dettagliatamente il dibattito degli scienziati, dei pensatori e degli enciclopedisti relativamente alla fisiologia, quella branchia della medicina che aveva come oggetto di studio la vita, il corpo, la salute dell' essere umano. Vengono quindi illustrate le posizioni di noti e meno noti pensatori e medici del Sei-Settecento che hanno ispirato Diderot, le quali permettono di mettere in evidenza la sua originalità di fronte alla tradizione. Per far ciò Paolo Quintili ripercorre le tappe che hanno portato alla formazione del testo: dapprima Diderot fa opera di epistemologo, raccogliendo e ordinando i saperi altrui, per poi passare ad elaborare un suo proprio punto di vista relativamente alla natura umana: gli Éléments de physiologie risultano così essere il culmine del progetto filosofico di Diderot, un tentativo di spiegare l'essere umano attraverso la scienza e non attraverso la metafisica, oltre che rappresentare un lavoro fine e documentato di epistemologia della scienza e della vita. L'opera si inserisce dunque a pieno titolo nel processo settecentesco di ridefinizione del concetto di natura e di essere umano, che si prefiggeva tra l'altro lo scopo di sostenere un approccio laico e scientifico allo studio del vivente. 
3 Dopo aver collocato il testo nel dibattito scientifico-filosofico del periodo, Paolo Quintili, entrando direttamente nelle pagine degli Éléments de physiologie, sintetizza le posizioni di Diderot, mettendone in luce l'originalità; Diderot contesta l'idea classica di natura pensata dagli antichi e riformulata da Cartesio, secondo cui la natura è un insieme fisso e stabile di esseri; per il philosophe la natura è, al contrario, un oggetto di esperienza mutevole, polimorfo, in continuo divenire; suo apporto originale è proprio l'integrazione del fattore tempo nella considerazione dei fenomeni naturali: il tempo trasforma i viventi, permette la metamorfosi da una specie all'altra (si pensi per esempio al bruco che diviene farfalla), cambiamento che non è una semplice variazione di aspetto, bensì un passaggio ontologico.

4 Un altro punto caratteristico del pensiero naturista di Diderot è la sua concezione di organizzazione fisica: gli organi si relazionano tra loro e con l'intero organismo secondo il criterio del bisogno; in altre parole la funzione di un organo è determinata dal bisogno che esso deve soddisfare, così come la forma è determinata dallo stesso principio organizzatore. Ne consegue l'idea che gli animali non si comportano secondo leggi morali, bensì secondo necessità, dettate dalla struttura del loro organismo e dai loro bisogni.

5 L'attenzione principale di Diderot è tuttavia riservata all'essere umano: come gli altri animali, anch'esso è fisicamente organizzato secondo i criteri della metamorfosi e del bisogno. Diderot analizza dettagliatamente gli organi del corpo umano, dalle fibre muscolari, al sangue, ai nervi, per concludere poi con fenomeni del cervello, quali i sensi, le passioni e il pensiero. È proprio in quest'ultima parte che meglio si esprime la posizione essenzialmente sensista e materialista di Diderot, il quale con quest'opera, si prefiggeva uno scopo innanzitutto etico e pratico: definire quali sono le condizioni concrete di realizzazione di una felicità fisica e morale per l'essere umano, considerato nella sua corporeità. Insomma, secondo Paolo Quintili gli Éléments de physiologie rappresentano un testo fondamentale per la comprensione del pensiero di Diderot, un testamento spirituale di un filosofo biologista, il più solido banco di prova di un nuovo ideale laico e naturalistico di antropologia. 